\title{
Correction: Evaluation of water displacement energetics in protein binding sites with grid cell theory
}

Cite this: Phys. Chem. Chem. Phys. $2015,17,16213$

G. Gerogiokas, ${ }^{a}$ M. W. Y. Southey, ${ }^{\text {b M. P. Mazanetz, }},{ }^{\text {}}$ A. Hefeitz, ${ }^{\text {b }}$ M. Bodkin, ${ }^{b}$ R. J. Law ${ }^{b}$ and J. Michel*a

DOI: $10.1039 / \mathrm{c5cp} 90084 \mathrm{k}$

Correction for 'Evaluation of water displacement energetics in protein binding sites with grid cell theory' www.rsc.org/pccp by G. Gerogiokas et al., Phys. Chem. Chem. Phys., 2015, 17, 8416-8426.

The authors would like to point out that the name of the fourth author, A. Hefeitz, has been spelt incorrectly. The correct author name should appear as A. Heifetz.

The Royal Society of Chemistry apologises for these errors and any consequent inconvenience to authors and readers.

${ }^{a}$ EaStCHEM School of Chemistry, Joseph Black Building, The King’s Buildings, Edinburgh, EH9 3JJ, UK. E-mail: mail@julienmichel.net

${ }^{b}$ Evotec (UK) Limited, 114 Innovation Drive, Milton Park, Abingdon, Oxfordshire, OX14 4SA, UK 